\title{
Volcanic monsoon influence revealed from multi-proxy evidence
}

\author{
Chaochao Gao
}

\begin{abstract}
High-resolution hydrological reconstructions incorporating multiple proxies from diverse monsoonal regions provide improved understanding of how monsoon precipitation responds to volcanic eruptions and the underlying mechanisms.
\end{abstract}

Large volcanic eruptions inject sulfate gases into the stratosphere to form aerosols and cool the Earth's surface by reflecting sunlight. This effect on temperature has been well acknowledged and has inspired proposals for stratospheric sulfate aerosol injection as a potential way to reduce global warming. However, precipitation responses to volcanic perturbation, especially in monsoon regions, are just as crucial. Land precipitation and runoff showed a substantial reduction after the 1991 Pinatubo eruption, causing widespread drought for a large number of people in the world (Trenberth and Dai 2007). The 1912 Katmai and 1982 El Chichón eruptions preceded three of the four driest Sahelian summers during the last century, with the last drought attributed to up to 250,000 deaths and 10 million refugees (Haywood et al. 2013).

Ice-core reconstructions (Gao et al. 2008; Sigl et al. 2014) suggest that over the past 2000 years, volcanic eruptions can be even larger than the aforementioned events. For example, the 1257 Samalas, 1452-53 Kuwae and 1815 Tambora eruptions are estimated to have produced three to eight times more sulfate aerosols than Pinatubo. What impact did these historical eruptions have on the monsoon system? And what are the underlying mechanisms at work?

\section{Multi-proxy evidence of}

\section{volcanic monsoon influence}

Recent progress on paleo-hydrological reconstructions provides a great opportunity to tackle these questions. Derived from over 300 precipitation, sensitive treering records, the Monsoon Asia Drought Atlas (MADA; Cook et al. 2010) offers a major reconstruction of summer monsoon precipitation over the past seven centuries in Asia. Using MADA, Anchukaitis et al. (2010) found conditions drying significantly in eastern and northern China, but wetter conditions in Southeast Asia, after large volcanic eruptions. The South Asian summer monsoon index (SASMI; Shi et al. 2014), based on 15 tree-ring chronologies, also shows that volcanic perturbations lead

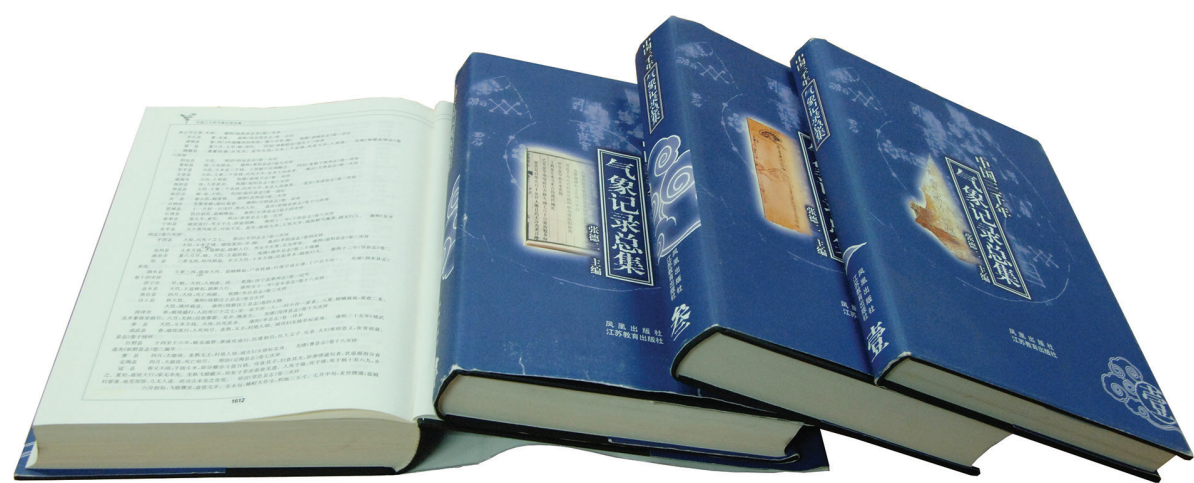

Figure 1: "A Compendium of Chinese Meteorological Records of the Last 3,000 Years" compiles the most comprehensive collection of Chinese official records including state annals, provincial annals, and county annals.

to a weak South Asian summer monsoon in the second post-eruption year. This, in combination with temperature reductions may be responsible for $69 \%$ of the historical droughts and famines in India over the last millennium (Shi et al. 2014).

Historical documents offer another independent line of evidence, and one of the best-preserved historical archives can be found in China. Shen et al. (2007) compiled a 500-year drought and flood index from historical rainfall descriptions in 120 stations across China, and found that the three most severe drought events in eastern China were triggered or amplified by volcanic eruptions. Zhuo et al. (2014) took the disaster records from a comprehensive collection of county, provincial, and state annals, and compiled an annual and county specific drought index over China for the past 700 years (Fig. 1). Overlapping MADA and this human archive with two independent multi-ice-core reconstructions of past volcanism, they studied the effects of volcanic eruptions on monsoon China over the past seven centuries. They found that large Northern Hemisphere eruptions cause notable drought in eastern China, and the severity increases with the injected amount of sulfate aerosols (Fig. 2). These Chinese annals adopt uniform recording standards and are rich in precipitation records, and therefore are a direct complement to the tree ring data. Similar studies utilizing historical records were conducted in various monsoon regions such as Sri Lanka and India (Sinha et al. 2011).

Proxy-model comparison and hints about the underlying mechanisms Iles and Hegerl (2014) showed monsoon regions dried significantly after large volcanic eruptions in the Coupled Model Intercomparison Project Phase 5 (CMIP5model ensemble results), and Man et al. (2014) reported a coherent summer precipitation reduction centered in central eastern China in the Max Plank Institute Earth System Model. In a preliminary superposed epoch analysis with the Community Earth System Model (CESM) and the Community Climate System Model (CCSM4) millennial outputs, we found a notable (significant at $95 \%$ confidence level) summer precipitation decrease in year 0-1 following the eruptions (Fig. 2). Therefore, proxy reconstructions and model simulations tend to agree on the average sign of monsoon response to large eruptions.

The summer monsoon contributes about $70 \%$ of the annual rainfall in eastern China, and it is affected by three airflows at 850 hPa: strong southwesterly winds from the Indian summer monsoon, a moderate 

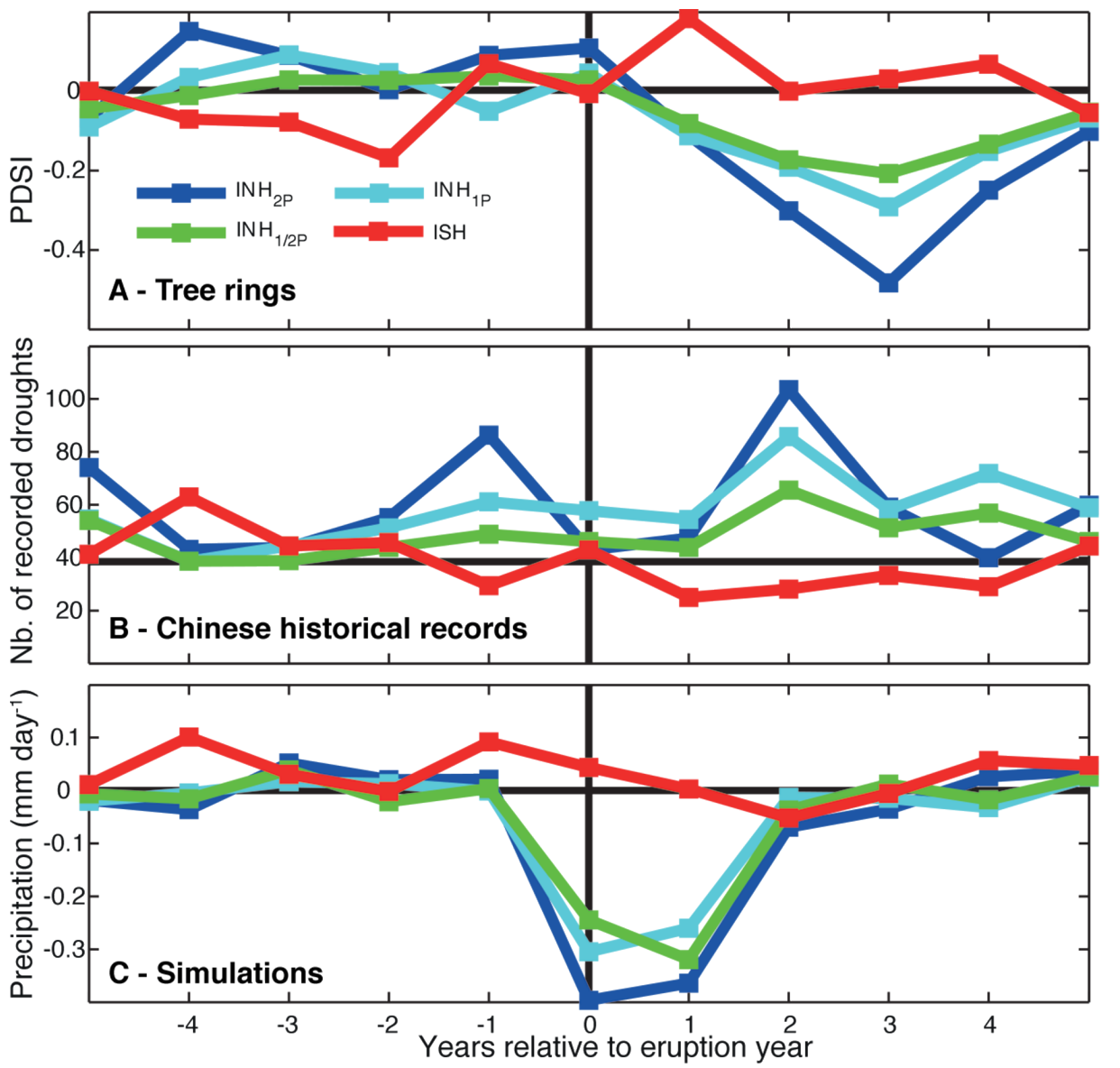

Figure 2: Average summer rainfall response in China to volcanic perturbations, revealed from (A) tree rings (Monsoon Asia Drought Atlas), (B) Chinese historical records (CHI), and (C) CESM and CCSM4 millennium simulations. Plotted are the superposed epoch analysis results for eruptions with Northern Hemisphere sulfate injection of more than half (INH1/2P), equal (INH1P), and double (INH2P) that of the 1991 Pinatubo eruption and SH-only (ISH) injection during AD 1300-1850. (A) and (B) are adapted from Zhuo et al. (2014); (C) is the precipitation anomaly with respect to the AD 1300-1850 mean.

southeast Asian monsoonal airflow from the west Pacific, and a weak cross-equatorial airflow from Australia. Model simulation shows significant reduction in water-vapor transport by both the southwesterlies and the southeasterlies after large tropical eruptions, therefore suggesting that the mechanism may be that volcanic-induced cooling reduces the zonal and meridional land-sea thermal contrast which leads to a weaker summer monsoon circulation.

\section{Proxy evidence of a volcano- monsoon mechanism}

A rapidly emerging body of proxy data (Sinha et al. 2011) suggests that, in addition to acting like a continental scale thermally-driven sea breeze, regional monsoons are interactive components of a singular global system tied to the seasonal migration of the intertropical convergence zone (ITCZ). Cooler temperature anomalies in the extratropical Northern Hemisphere could strengthen the NE trade winds in the Atlantic and Pacific basins, and force a southward shift of the ITCZ (Broccoli et al. 2006). The shift of ITCZ not only suppresses the mean state of the monsoon, but also intensifies the ENSO variability that further weakens the Asian Monsoon (Sinha et al. 2011).

The drying tendency after the Northern Hemisphere eruptions and wetting tendency after Southern Hemisphere ones (Haywood et al. 2013; Zhuo et al. 2014) indicate that volcanic aerosols may move the ITCZ toward the warmer hemisphere. A 500-year stalagmite $\delta^{13} \mathrm{C}$ reconstruction of rainfall in southern Belize (Ridley et al. 2015) identified nine drying events associated with large Northern Hemisphere eruptions, and conversely increased rainfall after Southern Hemisphere eruptions. As the site is located near the northern edge of the ITCZ and therefore sensitive to even minor shifts in the ITCZ's position, these results tend to confirm that asymmetric distribution of volcanic aerosols could cause short-lived ITCZ migration to the warmer hemisphere.

On the other hand, Hong et al. (2015) synthesized diverse rainfall archives from both the Asian and Australian monsoon regions and found synchronized retreat of ITCZ in both areas during the Little Ice Age. The authors suggested that a reduction in effective solar irradiance, including volcanically-induced events, supplemented by the unique continent-marine distribution in the west Pacific, could cause a contraction of the ITCZ and reduced seasonal extremes in monsoon moisture transport.

\section{Outlook}

Analyzing proxy records provides a valuable approach to exploring the monsoonal response to volcanic perturbations, and for the pre-instrumental period, the only approach. The monsoon region is home to more than half of the world's population, and results from the proxy analyses reveal how damaging volcanic monsoonal responses could be. Nevertheless, proxy reconstructions can be limited by spatial-temporal coverage and the sensitivity towards the parameters under examination. Integrating multiple proxies, including tree rings, ice and lake sediments, speleothems, and historical records, from all of the monsoon regions is therefore crucial to obtaining a better understanding of the impact of volcanic events on the monsoon regime, before the next big eruption or prior to any attempts at climate engineering through deliberate release of sulfate aerosols into the stratosphere.

\section{ACKNOWLEDGEMENTS}

This work is supported by the National Key Basic Research Program of China (2015CB953601). Thanks to Alan Robock for his help editing this paper.

\section{AFFILIATIONS}

Department of Environmental Science, Zhejiang University, Hangzhou, China

\section{CONTACT}

Chaochao Gao: gaocc@zju.edu.cn

REFERENCES

Anchukaitis KJ et al. (2010) Geophys Res Lett 37, doi: 10.1029/2010GL044843

Broccoli AJ et al. (2006) Geophys Res Lett 33, doi:10.1029/2005GL024546

Cook ER et al. (2010) Science 328: 486-489

Gao C (2008) J Geophys Res 113, doi:10.1029/2008JD010239

Haywood J et al. (2013) Nature Clim Change 3: 660-665 Hong $Y$ et al. (2015) Nature Geosci 8: 315-320 Iles CE, Gabriele CH (2014) Environ Res Lett 9, doi:10.1088/1748-9326/9/10/104012 Man W et al. (2014) J Climate 27: 7394-7409 Ridley HE et al. (2015) Nature Geosci 8: 195-200 Shen CM et al. (2007) Clim Change 85: 453-471 Shi F et al. (2014) Sci rep 4, doi: 10.1038/srep06739 Sigl M et al. (2014) Nature Clim Change 4: 693-697 Sinha A et al. (2011) Quat Sci Rev 30: 47-62 Trenberth KE, Dai A (2007) Geophys Res Lett 34, doi: 10.1029/2007GL030524

Zhuo ZH et al. (2014) J Geophys Res 119: 6638-6652 